Уфимцева Е.В

\title{
ПРИНЦИПЫ ПРАВА КАК КРИТЕРИЙ РАЗГРАНИЧЕНИЯ ОТРАСЛЕЙ В СИСТЕМЕ ПРАВА: ТЕОРЕТИЧЕСКИЙ АНАЛИЗ
}

Аннотация: Настоящая статья посвящена исследованию актуальной для современной юриспруденции проблемы разграничения отраслей в системе отечественного права. В статье освещается один из субсидиарных критериев отраслеобразования, наиболее часто упоминаемый в современной исследовательской литературе - принципы права. Автором характеризуется природа принципов права, в том числе с точки зрения наличия в ней объективного и субъективного начал, местоположение принципов права в системе права, их основные функции и значение для организации нормативного материала внутри системы права. В статье обосновывается возможность использования принципов права в качестве субсидиарного критерия отраслеобразования, приводятся соответствующие примеры. Кроме того, автором статьи приведены, проанализированы и прокомментированы взгляды советских и современных отечественных теоретиков права на принципы права, их роль в процессе организации нормативного материала в системе права. Научная новизна статьи заключается в специильном исследовании принцฺипов права как самостоятельного критерия разграничения отраслей в системе права. Подобные исследования в современной юридической науке в настоящее время не встречаются. Настоящая статья будет представлять интерес для широкого круга читателей: как для исследователей системы права и критериев отраслеобразования, так и для правоведов-отраслевиков и практикующих юристов. Ключевые слова: Система права, структура системы права, критерии отраслеобразования, принципь права, объективное в праве, субъективное в праве, правовое регулирование, система законодательства, нравственнье иенности права, законотворчество.

Abstract: This article is dedicated to the examination of a relevant for the modern jurisprudence issue of separation of branches within the system of Russian law. The work covers one of the commonly referred to within the modern scientific literature subsidiary criteria of branch-formation - the principles of law. The author gives characteristics to the nature of the principles of law, including from the perspective of presence of the subjective and objective beginnings; place of the principles of law in the system of law; their main functions and importance for organization of the normative material within the frameworks of the legal system. The author substantiates the possibility of implementation of the principles of law as the subsidiary criterion of branch-formation, as well as presents the corresponding examples. Moreover, the article illustrates the opinions of the Soviet and modern Russian theoreticians of law the principles of law, as well as their role in the process of organization of the normative material in the legal system. The scientific novelty consists in a special examination of the principles of law as the independent criterion of differentiation of the branches in the legal system. This article is intended for a broad audience of readers, as there is no similar research on this topic in the modern juridical science.

Keywords: Moral values of law, legislative system, legal regulation, the subjective in law, principles of law, the objective in law, criteria of branch-formation, structure of the legal system, legal system, lawmaking.

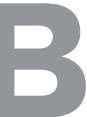
опрос об элементном составе системы отечественного права был и, пожалуй, остается одним из наиболее дискуссионных в отечественной юриспруденции. Примерно с конца 30-х гг. XX в. советские теоретики занялись углубленным исследованием вопросов понимания и описания права как системы, выяснением структурного строения данной системы и, конечно, изучением факторов, определяющих данное строение. Острые дискуссии отечественных ученых о системе права, с особой силой разгоревшиеся в 50-60-х гг. прошлого века, достаточно поутихли к концу 80-х - началу 90-х гг. Однако вскоре российские исследователи вновь обращаются к анализу обозначенной проблематики: за последние 10-15 лет публикуется множество научных статей, монографий, защищаются кандидатские и докторские диссертации, посвященные исследованию системы права и ее структуры. Вместе с тем, не смотря на внушительное количество научных работ, множество проблемных вопросов в данной области по-прежнему остаются для теории права дискуссионными и мало изученными. Это вопросы, касающиеся соотношения понятий «система права» и «структура права», соотношения системы права и системы законодательства, элементного состава структуры системы права и некоторые другие. Одним из наиболее «больных» для отечественной теории права по-прежнему остается вопрос о критериях разграничения отраслей права (которые, согласно предложению исследователя А.А. Головиной, весьма удачно, на наш взгляд, можно 
именовать «критериями отраслеобразования» $[1,4])$. Данный вопрос не был окончательно разрешен ни в рамках советских теоретических дискуссий о системе права, ни, как представляется, в рамках исследований современных авторов.

Прежде всего, отметим, что в современной исследовательской литературе в продолжение советской научной традиции большинство авторов придерживаются точки зрения о том, что главными, определяющими критериями разграничения отраслей в системе права являются предмет и метод правового регулирования. Указанной точки зрения придерживаемся и мы. Однако в рамках настоящей статьи посвятим свое внимание анализу одного из так называемых «субсидиарных», дополнительных критериев отраслеобразования, достаточно часто упоминаемого в современной исследовательской литературе - принципам права.

Принципы права, без сомнения, - одна из наиболее сложных и спорных категорий юридической науки. Единства в понимании принципов права в научных кругах не было прежде, и не существует в настоящее время. Обратимся ненадолго к различным аспектам характеристики сущности данной правовой категории.

Что в целом понимается под категорией «принцип»? В дословном переводе с латинского «principium» означает «начало, основа». В философской советской энциклопедии данное понятие определяется как «то же, что и основание, т.е. то, что лежит в основе некоторой совокупности фактов или знаний» [2]. В современных энциклопедиях данному понятию в частности дают следующие определения: «в субъективном смысле основное положение, предпосылка; в объективном смысле исходный пункт, первооснова, самое первое» [3]; «исходное, не требующее доказательств положение теории; внутреннее убеждение, неизменная позиция или правило поведения» [4]. Отметим, что, исходя из представленных дефиниций, понятие «принцип» трактуется как в субъективном, так и в объективном смыслах.

Действительно, говоря «принцип», мы, как правило, подразумеваем нечто, положенное в самое основание, некоторую первооснову, отправную точку. Причем, эта первооснова как бы самоочевидна, не требует доказательства, в своем роде она истинна.

Категория «принцип», а также упоминания о различных видах принципов (этических, нравственных, управленческих и т.д., в том числе и правовых) встречается в трудах таких выдающихся дореволюционных правоведов, как Н.М. Коркунова [5, 29], И.А. Покровского, Г.Ф. Шершеневича [6, 205], И.А. Ильина
$[7,85]$. Однако подробного описания сущности и природы принципов права и принципа как такового в работах указанных авторов не содержится.

Рассуждения о принципах права (юридических принципах) мы можем встретить в трудах еще одного правоведа дореволюционного периода С.А. Муромцева [8, 154]. Говоря о принципе вообще, ученый писал: «То, что называют принципом, есть, в сущности, только обобщенное описание или выражение совокупности общих свойств («общего смысла») существовавшего или существующего порядка, существовавших или существующих правил, отношений, действий». Что же касается юридического принципа, то ученый указывал: «...юридический принцип выражает собой явление истории права, или, точнее, некоторую совокупность историко-юридических явлений. Юридический принцип служит формулой, которая определяет так или иначе известную группу правовых отношений и соответствующих им правовых постановлений»; «юридический принцип указывает на то, что должно быть... составляет продукт человеческой деятельности... может быть нарушен человеком... подлежит критике». Так С.А. Муромцев описывал юридический (правовой) принцип в его соотношении с законом. При этом закон понимался им как явление в высшей степени объективного порядка, а юридический принцип, очевидно, как явление субъективного рода.

Что, все-таки, в сущности есть принцип права? Какова его природа? И в какой момент принцип становится правовым - изначально таковым «рождается», «эволюционирует» в правовой или как-то иначе? Какое место принцип занимает в системе права? - Этими вопросами основательно задались ученые-правоведы советского периода. Сразу стоит оговориться, что и в прошлом, и в настоящее время определение понятия «принципы права» находится в большой зависимости от типа правопонимания, и, как нам представляется, дать данной категории исчерпывающее, полное и окончательное определение не представляется возможным.

В основном исследователи советского периода времени понимали принципы права как некие руководящие идеи, «отправные точки» в праве (Л.С. Явич, Б.В. Шейндлин, Н. Г. Александров и др.) [9, 26-29] [10, 13-14] [11, 16-29]. Большинство авторов склонялись к определению природы принципов права как объективно-субъективной, однако существовала и точка зрения о полной субъективности правовых принципов и их непригодности по этой причине для разграничения отдельных отраслей в системе права (М.Д. Шаргородский, О.С. Иоффе) [12, 349]. Некоторые 
из советских авторов, напротив, напрямую говорили о возможности использования принципов права как критерия разграничения отраслей в его системе (Б.В. Шейндлин, Л.И. Дембо и др.). Причем Л.И. Дембо, можно сказать, абсолютизировал значение принципов права в процессе разграничения его отраслей [13, 88-98], однако мы не склонны к аналогичной оценке их значимости для процесса отраслеобразования, о чем еще будет упомянуто далее.

Впервые как реальный элемент структуры права принцип права был описан С.С. Алексеевым. Ученый, изучая систему права, отводил в ней принципам права совершенно особое место. Прежде всего, отметим, что принципы права рассматривались С.С. Алексеевым именно как реальный элемент системы права, а не просто как «идея», некая абстрактная общность. Тем не менее, именно в принципах, по мнению автора, отражалось идейное и волевое содержание права $[14,21]$. В целом С.С. Алексеев был склонен считать принципы права особого рода нормативным предписанием (нормой права). Однако следует признать, что, основываясь на подобном подходе, определить положение таких нормативных предписаний в системе права весьма нелегко, ведь среди принципов существуют не только отраслевые «в чистом виде», но и общеправовые, и межотраслевые, которые достаточно сложно четко отнести к конкретному «адресу» в структуре системы права.

С.С. Алексеев предлагал разрешать обозначенную проблему, опираясь на выработанные в философии теоретические положения об активном центре целостного системного образования. С одной стороны принципы понимаются как нормативное предписание, но с другой - это нормативное предписание, являющееся «одухотворяющим началом права» [14, 88]. Посредством него право как бы связывается с реальными общественными отношениями. Именно поэтому принципы права ученый предлагал считать «активными центрами» его системы. Вместе с тем, стоит отметить, что, в целом соглашаясь с подобным пониманием принципов права, мы все же не можем с точностью ответить на вопрос, поставленный еще О.С. Иоффе: какое именно положение в структуре системы права занимают его принципы? Нам понятна их роль и значение, однако четкое отнесение их к определенному уровню системы права также, безусловно, важно.

Представляется, что принцип права - особый элемент его системы. И данный элемент действительно выполняет определенную связующую, ориентирующую функцию, причем не только для процесса правового регулирования, применения права и т.д., но и непосредственно для самой системы права - ее «самоорганизации», «самоупорядочения». Принцип права, будучи идейным центром, как бы не является непосредственным «строительным» элементом института, отрасли или системы права в целом, как самый первичный и простейший элемент системы права - норма права. Да, принцип непосредственно включен во внутреннее нормативное содержание права, но его роль в данном содержании особенна. К примеру, если рассматривать абстрактную модель отрасли права, то она включает в себя ряд правовых институтов, которые, в свою очередь, являются упорядоченной совокупностью определенных норм права. Принципы данной отрасли права, по нашему мнению, не будут структурно входить ни в один из институтов отрасли, они как бы «стоят особняком». В самом деле, к какому отдельному институту в процессуальных отраслях права можно отнести, скажем, принцип независимости судей? Или языка судопроизводства? Данные принципы определяют «общее направление» отрасли, идейно пронизывают все ее нормативное содержание. Вместе с тем принципы, как представляется, все же оказывают определенное влияние на содержание и структуру ряда институтов соответствующей отрасли, а в дальнейшем - на процесс их «работы», функционирования в системе права, реализации и применения их предписаний к конкретным общественным отношениям с целью их урегулирования. К примеру, принцип гласности в процессуальных отраслях влияет как на форму проведения судебных заседаний по отдельным категориям дел (открытых или закрытых), так и на организацию обеспечения доступа всех желающих лиц к результатам рассмотрения конкретного дела (доступность информации о стадиях движения дела и принимаемых процессуальных решениях на сайтах судов, публикация решения суда в сети Интернет в официальных источниках и т.д.). Принцип языка гражданского судопроизводства определяет не только порядок ведения судебного разбирательства и составления процессуальных документов, но и оказывает влияние на процедуру выбора и привлечения к участию в деле переводчика, условия и форму реализации его полномочий и ответственность. На примере материальных отраслей права хорошим образцом может быть принцип свободы договора в гражданском праве: данный принцип «отражается» во всех без исключения нормах, касающихся конкретных видов договоров, их условий, порядка изменения и т.д., а также ярко проявляется в возможности участников гражданского оборота заключить договор, прямо не предусмотренный положениями гражданского законодательства. 
В настоящее время некоторые исследователи говорят о процессе формирования принципов отдельных институтов права. В самом деле, в структуре некоторых крупных отраслей современного отечественного права существует достаточное большое количество институтов, в рамках которых уже началось формирование общих начал правового регулирования. Именно эти общие начала некоторые исследователи именуют принципами институтов. Безусловно, вопрос о том, могут ли такие «отправные точки» в рамках института в силу степени своей «абстрактности» и регулятивного потенциала считаться принципами права, является непростым. Тем не менее, названные общие начала регулирования оказывают влияние на структуру и нормативное содержание соответствующего института в целом. Например, принцип обеспечения права работников на участие в управлении организацией (как его именует Трудовой кодекс РФ в ст. 2), на наш взгляд, в значительной степени определяет содержание многих нормативных положений в рамках соответствующего института трудового права - института социального партнерства в сфере труда. В рамках данного института подробно и в соответствии с указанным принципом регламентировано, какими могут быть органы социального партнерства, кто может являться представителем работников в социальном партнерстве, правила организации коллективных переговоров, заключения коллективных соглашений, формы участия работников в управлении делами организации и мн.др.

Что касается межотраслевых принципов, то они напрямую не могут быть отнесены к структуре одной определенной отрасли права (или одновременно отнесены к структуре нескольких отраслей права). Они как бы «работают» сразу на несколько направлений, при этом являясь определенным связующим звеном для нескольких структурных образований - отраслей в системе права. Например, презумпция невиновности, провозглашенная Конституцией РФ, одинаково раскрывает свое содержание как в рамках уголовного, так и в рамках административного права: лицо подлежит ответственности только за то общественно-опасное деяние, в отношении которого установлена его вина. Данный принцип полностью «пронизывает» содержание указанных отраслей права и определяет в целом характер правового регулирования широкого круга общественных отношений в соответствующих областях: условия и порядок признания недопустимыми доказательств по делу, порядок оценки доказательств, порядок вынесения оправдательного или обвинительного вердикта присяжными заседателями в уголовном процессе, основания и порядок прекращения про- изводства по уголовному или административному делу в связи с отсутствием в действиях лица состава правонарушения и т.д. Также аналогично в каждой из процессуальных отраслей российского права раскрываются такие межотраслевые принципы, как принцип гласности и открытости судебного разбирательства, непосредственности, непрерывности и устности разбирательства, несменяемости судей и др.

Наконец, что касается общеправовых принципов, то и они, совершенно определенно, не могут быть отнесены к какой-то одной структурной общности системы права. Они существуют как бы «отдельно» от всех структурных элементов системы, находясь, однако, при этом с ними в теснейшей связи и теснейшем взаимодействии. Они выполняют объединяющую, интегрирующую и упорядочивающую функцию для всей системы права в целом, «связывают» все структурные элементы этой системы между собой в определенной закономерности, оставаясь при этом такими же элементами структуры (к данной категории, безусловно, можно отнести такие базовые принципы права, как справедливость, гуманность, демократизм, системность и иные). Следует отметить, что принципы данной группы обладают наивысшей степенью абстрактности, универсальности и всеобщности. И они, безусловно, не могут быть использованы в процессе разграничения отраслей в системе права в качестве субсидиарного критерия.

Мы не склонны определять принципы права просто как некие «идеи», «общие положения», «отправные точки», поскольку в противном случае нам не удается объяснить, каким образом принципы права способны оказывать реальное регулятивное воздействие на общественные отношения, упорядочивать их. Для этих целей, как представляется, нужно обладать практически теми же признаками, что и норма права. Действительно, принципы права, так или иначе, задают определенную направленность поведения, направленность деятельности в правовом поле, направленность правового регулирования. Это рассматривается нами как своего рода правило поведения, хотя и сформулированное достаточно абстрактно. Движемся далее. Это правило поведения - формально определено, закреплено (или как минимум - провозглашено) в тексте конкретного нормативно-правового акта. Мы не склонны соглашаться с теми авторами, которые видят принципы права вне его нормативного содержания (каковы тогда критерии отнесения таких принципов к категории «правовых», если не их признание в качестве таковых законодателем?). Принцип права - «правило поведения», распространяющее свое действие на неопределенный круг лиц и рас- 
считанный, безусловно, на многократное применение. Наконец, принцип права действительно способен регулировать общественные отношения не просто через более конкретные нормы права, но и самостоятельно. В литературе достаточно часто в этом отношении приводятся примеры (правильные, тем не менее), касающиеся аналогии права. В ситуации, когда отсутствует норма права, необходимая для регуляции определенных общественных отношений (которые в такой регуляции все же нуждаются), правовое регулирование осуществляется путем непосредственного действия принципов права. Правоприменитель в данном случае выносит свое решение по конкретному делу, основываясь на предписаниях того или иного принципа права, и такое решение правоприменителя, во-первых, действительно упорядочивает общественные отношения, и, во-вторых, имеет нисколько не меньшую юридическую силу, чем принятое в соответствии с предписаниями конкретных норм права. Наконец, отступление от принципов права может влечь за собой определенные негативные последствия (отказ в защите гражданских прав, признание недобросовестным налогоплательщиком в рамках налоговых правоотношений и мн.др.).

Тем не менее, в целом не стоит отождествлять принцип права с нормой права. Принцип права, все-таки, очень специфичен по своему содержанию (максимально абстрактен), и выполняет сразу несколько ролей, в отличие от нормы права (у нее основная роль - регулятивная): выражает идейное и сущностное содержание права, направляет действие системы права в целом и отдельных ее элементов в частности, организует их, и, наконец, также может выполнять непосредственную регулятивную функцию. Наконец, принцип права и норма права имеют различные структуру и механизм действия.

Что касается природы принципов права, то стоит согласиться с мнением, что в большинстве своем они обусловлены общественными отношениями, практикой их существования, закономерностями развития системы права - то есть явлениями объективного порядка. С другой стороны, как справедливо отмечали еще О.С. Иоффе и М.Д. Шаргородский, принципы формулируются законодателем, являются в своем роде продуктом его творчества, находят свое отражение в нормативном массиве посредством его воли. В этом выражается субъективная сторона сущности принципов права. Мы не можем полностью согласить с мнением, что принципы права необходимо «открыть», «обнаружить» в системе права. Такое утверждение постулирует, на наш взгляд, полную автономность принципов права, их оторванность от сознания, что, как представляется, не характерно и для самой системы права в целом.

Современные авторы также по-разному определяют принципы права и их место в системе отечественного права. Ряд исследователей определяют принципы права как основные, руководящие идеи в праве (Д.М. Азми, А.Л. Захаров, О.А. Потапова, Н.С. Шерстнева) [15] [16] [17, 6] [18, 11-12], особые предписания, являющиеся элементами его системы, но не тождественные нормам права (С.Е. Фролов) $[19,4]$, как особую форму права (В.В. Ершов) [20], как нормы права общего характера (А.С. Сидоркин) $[21,8]$. При этом некоторые авторы особо подчеркивают объективность природы принципов права. Например, В.В. Ершов отмечает, что принципы права должны находиться в зависимости «не от субъективного усмотрения законодателя, а от объективно существующих и изменяющихся общественных отношений» [20, 7]; А.Л. Захаров характеризует принципы права как «основные идеи, отражающие закономерности и связи развития общественных отношений, нормативно закрепленные в позитивном праве, направляющие правовое регулирование и определяющие сущность и социальное назначение права» [16, 7]; Д.М. Азми пишет: «Объективность принципов права предопределена тем, что они отображают данные о сути и константных закономерных положениях, идеях самого права» $[15$, 10]. Однако наравне с объективностью природы принципов отмечается и ее субъективный момент - принципы признаются продуктом творчества законодателя (А.Л. Захаров, Н.С. Шерстнева).

В современной литературе также высказывалось мнение о возможности использования принципов права в качестве дополнительного критерия дифференциации правовых норм по отраслям системы права (Д.М. Азми, А.Л. Захаров), однако механизм такого использования подробно не описывался. Некоторые авторы, в свою очередь, отвергают такую идею по причине субъективности природы принципов права и возможности их применения, исходя из абсолютно субъективных точек зрения и целей каждого из исследователей (А.А. Головина) $[1,20]$.

Практически все современные исследователи классифицируют принципы права в зависимости от их структурного «положения» в системе права. Кроме того, большинство исследователей склоняются к выводу о том, что принципы права должны находить свое обязательное отражение в действующем законодательстве, иметь закрепление в рамках нормативноправовых актов. Однако некоторые авторы считают, что принципы права могут иметь свое закрепление, к 
примеру, в рамках правовой доктрины или судебной практики (Н.С. Шерстнева). Еще одна группа исследователей различает между собой понятия «принципы права» и «правовые принципы»: первые, по их мнению, должны находить свое отражение в писаном законодательстве, официальных нормативно-правовых актах, вторые - находят свое отражение в иных источника - судебной практике, правовых обычаях и т.д. (В.В. Ершов). И практически единодушны исследователи в том, что посредством принципов права выражается сущность права.

Мы определили, что принципы права являются реальным элементом системы права, выражающим сущность и волевое, ценностное содержание права и обладающим реальным регулятивным потенциалом. Прежде, чем перейти к вопросу о возможности использования принципов права как критериев разграничения отраслей права в его системе, стоит сказать несколько слов о процессе их формирования.

Предполагается, как отмечалось ранее, что принцип права не просто возникает «из ниоткуда», «сам по себе», или, напротив, полностью «придумывается законодателем», а постепенно «складывается», основываясь на практике определенной группы общественных отношений. С течением времени правовое регулирование этих отношений начинает следовать некоторой «схеме», некоторому общему направлению в соответствии с характером этих отношений, типу самого общества, уровню экономического развития, его культуре, мировоззрениям, традициям, обычаям. Вообще стоит вспомнить, что право - весьма «многоликое» явление. И его сущность, его базовые ценности зависят от огромного количества факторов. Они могут меняться с историческим ходом времени, со сменой политических режимов, экономического строя. Соответственно, в зависимости от этого будут меняться и принципы права.

Итак, с процессом складывания, изменения определенной группы общественных отношений, появления норм права, предназначенных для их урегулирования, формирования механизма правового регулирования параллельно идет процесс формирования принципов права. Безусловно, такие принципы в конечном итоге должны быть выражены, «оформлены» законодателем. Только после включения непосредственно в нормативный массив, в систему права такие принципы можно будет назвать «правовыми» в полном смысле этого слова, только когда они начинают «жить» в правовом поле.

Каким образом принцип права может быть использован в качестве дополнительного критерия дифференциации отраслей права в его системе? Отметим сразу, что в этих целях, на наш взгляд, «пригодны» только межотраслевые и отраслевые принципы права, поскольку общеправовые принципы максимально абстрактны и «обслуживают» всю систему права в целом, а принципы отдельных правовых институтов (если согласиться с возможностью существования таковых) действуют на более низком структурном уровне системы права - институциональном. Прежде всего, содержание принципа указывает на «принадлежность» отрасли или группы отраслей к материальному или процессуальному праву. К примеру, принцип свободы договора явно указывает на принадлежность того нормативного комплекса, на который распространяется действие названного принципа, к группе материальных отраслей, поскольку он посвящен непосредственно регулированию содержания соответствующих общественных отношений, вопросам прав и обязанностей их участников, основаниям возникновения, изменения или прекращения этих прав и обязанностей и т.д. В свою очередь такие принципы, как гласность и устность, состязательность сторон и т.п. регламентируют процедуры рассмотрения юридических споров компетентными органами и явно указывают на принадлежность соответствующих норм к процессуальным отраслям права. Однако не только «функциональное предназначение» принципа имеет значение для определения отрасли права, но и его сущностное, содержательное наполнение. Любой принцип представляет собой определенный императив, но императив разного рода: принципы уголовного права, к примеру, основой своего содержания имеют правовые гарантии справедливости, гуманности, установления ответственности только за виновное поведение лица; принципы гражданского права, в свою очередь, - гарантию свободы воли участников гражданского оборота, возможность формирования ими своего, договорного режима регулирования возникающих между ними отношений; принципы трудового права - гарантию защиты прав трудящихся, обеспечение достойных условий труда и его оплаты, гарантии защиты прав разных категорий работников, обеспечение права на управление делами организации; принципы процессуальных отраслей права - правильное применение процедурных норм при рассмотрении конкретных юридических споров и вынесение законного и справедливого решения по конкретному делу и т.д. Таким образом, можно сказать, что каждый отдельно взятый правовой принцип имеет свою уникальную иель, и цель эта определяется характером тех общественных отношений, регулированию которых посвящен принцип. Получается, что цель действия и вообще существования каждого 
принципа объективна, а также в своем роде уникальна. Определив данную цель и раскрыв содержание конкретного принципа, мы вполне можем определить, во-первых, сферу правового регулирования, в которой он действует, и впоследствии - его отраслевую принадлежность. Что нам это дает?

На наш взгляд, определив, что к тому или иному нормативному образованию в системе права «привязан» конкретный правовой принцип, мы можем сделать следующий вывод: данное нормативное образование обладает определенной специфической особенностью, а вернее, этой особенностью, скорее всего, изначально обладают общественные отношения, регулированию которых и служит данное нормативное образование (о чем мы только что рассуждали). Специфичность общественных отношений как объективный фактор может, в конечном итоге, свидетельствовать о наличии специального предмета правового регулирования для целой отрасли права. Более того, существование правового принципа может свидетельствовать и о специфичности метода правового регулирования тех или иных общественных отношений - направление правового регулирования, его основные начала в конечном итоге зачастую определяют, с помощью каких средств и способов будет осуществляться такое правовое регулирование, следовательно, косвенно это вновь может указывать на существование самостоятельной правовой отрасли через метод правового регулирования. Например, принцип свободы договора явно свидетельствует, во-первых, о диспозитивном начале в методе регулирования соответствующих гражданских правоотношений, и, во-вторых, уже указывает на главный инструмент правового регулирования данных отношений - договор.

Однако все не так просто, каким может показаться на первый взгляд. Во-первых, прежде всего, необходимо разрешить вопрос о том, существует ли в действительности тот или иной правовой принцип. Проще, когда он четко сформулирован законодателем. Сложнее, когда принцип сформулирован абстрактно, либо «растворен» в нормативном массиве. Еще сложнее, когда за правовой принцип принимают несколько другие явления правовой действительности. Например, ряд авторов (как современных, так и в советское время) утверждают, что правовые принципы могут формулироваться в правоприменительной практике (А.Л. Захаров). Однако невозможно не отметить, что реальная правоприменительная практика иногда, мягко говоря, не вполне соответствует духу и букве закона, а иногда, к сожалению, может идти вразрез с его положениями. Стоит ли формирующуюся таким образом практику считать источником правовых принципов? Навряд ли, поскольку сущность и идейное, ценностное содержание права такая практика не выражает. Также необходимо отграничить принцип права от самих норм права, обладающих менее абстрактным характером и несколько иным содержанием и функциями, о чем уже упоминалось ранее.

Определенные проблемы могут возникнуть и при «отнесении» принципа права к конкретной группе - общеправовых, межотраслевых, отраслевых, поскольку в данном случае необходимо четко определить происхождение конкретного принципа и «сферу его деятельности», на нормы каких отраслей он распространяет свое организующее и направляющее действие. Еще раз подчеркнем, что ряд современных исследователей настаивают на выделении самостоятельной группы принципов отдельных правовых институтов, что в настоящее время представляется весьма обоснованным, поскольку в рамках ряда отраслей права оформились достаточно крупные правовые институты или даже подотрасли (право собственности, обязательственное право в гражданском праве, избирательное право в рамках конституционного права и т.д.), которые в силу своей специфики и объема нормативного содержания вполне могут предопределить формирование в своих рамках общих начал правового регулирования. При таких обстоятельствах необходимо особенно внимательно характеризовать тот или иной правовой принцип, его содержание, предназначение и место в системе права.

Кроме того, как еще в прошлом отмечали исследователи О.С. Иоффе и М.Д. Шаргородский, во-первых, некоторые принципы права носят межотраслевой характер, т.е. не могут быть «привязаны» к какой-то одной отрасли права, и, во-вторых, точное количество и сущность самих отраслевых принципов никем точно не установлены, они дискуссионны. Однако возразим, что это обстоятельство отнюдь не лишает нас возможность определить, является ли тот или иной элемент системы права в действительности правовым принципом, а также уточнить, к каким правовым общностям он привязан, его место в системе права.

Таким образом, мы приходим к заключению, что принципы права могут являться показателем юридического своеобразия определенного нормативного комплекса (института, отрасли права, группы отраслей или всего права в целом), которое, в свою очередь, может выступать свидетельством специфичности, во-первых, предмета правового 
DOI: $10.7256 / 1811-9018.2016 .8 .16374$

При цитировании этой статьи сноска на doi обязательна

Правоведение

регулирования (общественных отношений) определенных структурных подразделений системы права, и, во-вторых, метода правового регулирования этих отношений. Учитывая это обстоятельство, и объективную обусловленность принципов права, мы утверждаем о возможности их использования в качестве субсидиарного критерия разграничения отраслей в системе отечественного права.

\section{Библиография:}

1. Головина А.А. Критерии образования самостоятельных отраслей в системе российского права: Автореф. дисс. ... канд. юрид. наук. Москва, 2012. 34 с.

2. Философская энциклопедия. В 5-х т. Под ред. Ф. В. Константинова. М., Советская энциклопедия. 1960-1970. 2996 с.

3. Начала современного естествознания. Тезаурус. Под ред. В.Н. Савченко, В.П. Смагина. Ростов-на-Дону, Феникс. 2006. $336 \mathrm{c}$.

4. Новая философская энциклопедия. В 4-х т. Под ред. В.С. Степина. М., Мысль. 2001. 734 с.

5. Коркунов Н.М. Лекции по общей теории права. М., Н.К. Мартынов. 1914. 364 с.

6. Шершеневич Г. Ф. Общая теория права. Том 1-2. М., Издательство бр. Башмаковых. 1910. 407 с.

7. Ильин И.А. Общее учение о праве и государстве. М., Русская книга. 1994. 403 с.

8. Муромцев С.А. Определение и основное разделение права. М., Тип. А.И. Мамонтова и Ко. 1879. 250 с.

9. Явич Л.С. Система советского права и систематизация законодательства (тезисы сообщения) // Научная сессия, посвященная теоретическим вопросам систематизации советского законодательства. Тезисы докладов и сообщений. M., 1961.

10. Шейндлин Б.В. Развитие основных принципов советского права // Межвузовское научное совещание: «Сорок лет советского государства и права и развитие правовой науки». Тезисы докладов. Л., Изд. ЛГУ. 1957.

11. Александров Н.Г. Социалистические принципы советского права // Советское государство и право. 1956. № 8.

12. Иоффе О. С., Шаргородский М. Д. Вопросы теории права. М., Госюриздат. 1961. 380 с.

13. Дембо Л.И. О принципах построения системы права // Советское государство и право. 1956. № 8.

14. Алексеев С.С. Структура советского права. М., Юридическая литература. 1975. 264 с.

15. Азми Д.М. Историко-теоретический и методологический анализ системы права: Автореф. дисс. ... доктора юрид. наук. Москва, 2011. 44 с.

16. Захаров А.Л. Межотраслевые принципы права: Автореф. дисс. ... канд. юрид. наук. Казань, 2003. 31 с.

17. Потапова О.А. Принципы гражданского права: Автореф. дисс. ... канд. юрид. наук. Ульяновск, 2002.20 с.

18. Шерстнева Н.С. Принципы российского семейного права: Автореф. дисс. ... доктора юр. наук. Москва, 2007. 59 с.

19. Фролов С.Е. Принципы права: вопросы теории и методологии: Автореф. дисс. ... канд. юрид. наук. Кострома, 2001. 26 с.

20. Ершов В.В. Юридическая природа общих и гражданско-правовых принципов: Афтореф. дисс. ... канд. юрид. наук. Москва, 2009. 22 с.

21. Сидоркин А.С. Принципы права: понятие и реализация в российском законодательстве и судебной практике: Автореф. дисс. ... канд. юрид. наук. Москва, 2010. 26 с.

22. Уфимцева Е.В. С.С. Алексеев о системе права: взгляды на критерии отраслеобразования // Genesis: исторические исследования. - 2015. - 3. - С. 541 - 566. DOI: 10.7256/2409-868X.2015.3.15199. URL: http://www.e-notabene.ru/hr/article_15199.html

\section{References (transliterated):}

1. Golovina A.A. Kriterii obrazovaniya samostoyatel'nykh otraslei v sisteme rossiiskogo prava: Avtoref. diss. ... kand. yurid. nauk. Moskva, 2012. 34 s.

2. Korkunov N.M. Lektsii po obshchei teorii prava. M., N.K. Martynov. 1914. 364 s.

3. Shershenevich G. F. Obshchaya teoriya prava. Tom 1-2. M., Izdatel'stvo br. Bashmakovykh. 1910. 407 s.

4. Il'in I.A. Obshchee uchenie o prave i gosudarstve. M., Russkaya kniga. 1994. $403 \mathrm{s.}$

5. Muromtsev S.A. Opredelenie i osnovnoe razdelenie prava. M., Tip. A.I. Mamontova i Ko. 1879. 250 s.

6. Yavich L.S. Sistema sovetskogo prava i sistematizatsiya zakonodatel'stva (tezisy soobshcheniya) // Nauchnaya sessiya, posvyashchennaya teoreticheskim voprosam sistematizatsii sovetskogo zakonodatel'stva. Tezisy dokladov i soobshchenii. M., 1961.

7. Sheindlin B.V. Razvitie osnovnykh printsipov sovetskogo prava// Mezhvuzovskoe nauchnoe soveshchanie: «Sorok let sovetskogo gosudarstva i prava i razvitie pravovoi nauki». Tezisy dokladov. L., Izd. LGU. 1957.

8. Aleksandrov N.G. Sotsialisticheskie printsipy sovetskogo prava // Sovetskoe gosudarstvo i pravo. 1956. № 8.

9. Ioffe O. S., Shargorodskii M. D. Voprosy teorii prava. M., Gosyurizdat. 1961. $380 \mathrm{s.}$

10. Dembo L.I. O printsipakh postroeniya sistemy prava // Sovetskoe gosudarstvo i pravo. 1956. № 8.

11. Alekseev S.S. Struktura sovetskogo prava. M., Yuridicheskaya literatura. 1975. $264 \mathrm{~s}$.

12. Azmi D.M. Istoriko-teoreticheskii i metodologicheskii analiz sistemy prava: Avtoref. diss. ... doktora yurid. nauk. Moskva, 2011. $44 \mathrm{~s}$.

13. Zakharov A.L. Mezhotraslevye printsipy prava: Avtoref. diss. ... kand. yurid. nauk. Kazan', 2003. 31 s.

14. Potapova O.A. Printsipy grazhdanskogo prava: Avtoref. diss. ... kand. yurid. nauk. Ul'yanovsk, 2002.20 s. 
DOI: $10.7256 / 1811-9018.2016 .8 .16374$

При цитировании этой статьи сноска на dоі обязательна

Право и политика $8(200) \cdot 2016$

15. Sherstneva N.S. Printsipy rossiiskogo semeinogo prava: Avtoref. diss. ... doktora yur. nauk. Moskva, 2007. 59 s.

16. Frolov S.E. Printsipy prava: voprosy teorii i metodologii: Avtoref. diss. ... kand. yurid. nauk. Kostroma, 2001.26 s.

17. Ershov V.V. Yuridicheskaya priroda obshchikh i grazhdansko-pravovykh printsipov: Aftoref. diss. ... kand. yurid. nauk. Moskva, 2009. 22 s.

18. Sidorkin A.S. Printsipy prava: ponyatie i realizatsiya v rossiiskom zakonodatel'stve i sudebnoi praktike: Avtoref. diss. ... kand. yurid. nauk. Moskva, 2010. 26 s.

19. Ufimtseva E.V. S.S. Alekseev o sisteme prava: vzglyady na kriterii otrasleobrazovaniya // Genesis: istoricheskie issledovaniya. - 2015. - 3. - C. 541 - 566. DOI: 10.7256/2409-868X.2015.3.15199. URL: http://www.e-notabene.ru/hr/article_15199.html 